\title{
A IMPORTÂNCIA DA EDUCAÇÃO INFANTIL PARA O DESENVOLVIMENTO COGNITIVO DA CRIANÇA
}

\author{
João Guedes dos Anjos' ${ }^{1}$ \\ Patrícia da Silva Bispo ${ }^{2}$
}

\begin{abstract}
RESUMO
O presente artigo apresenta um estudo sobre a importância e influência do ensino da Educação Infantil para o desenvolvimento social, cognitivo e afetivo dos educandos. A educação infantil é a porta de acesso da criança às primeiras experiências em sociedade, é nesta fase da vida que ela tem a oportunidade de construir suas hipóteses e aprendizagens sobre o mundo; ampliar seus horizontes e experimentar novas vivências que servirão de subsídio para a sua construção identitária. Neste sentido, foi necessário conhecer um pouco mais sobre a trajetória e a instalação da Educação Infantil no Brasil para que chegássemos até o panorama da contemporaneidade. Na metodologia desta pesquisa foram utilizadas as abordagens qualitativa e descritiva, com a finalidade de refletir sobre os impactos positivos da Educação Infantil na vida educacional dos indivíduos. Após a coleta de informações constatou-se que o reconhecimento da criança enquanto sujeito social e histórico faz da Educação Infantil um passo imprescindível para legitimidade da cidadania e da infância.
\end{abstract}

Palavras-chave: Educação Infantil, Desenvolvimento Cognitivo, Aprendizagem.

\section{ABSTRACT}

This article presents a study on the importance and influence of Early Childhood Education for the social, cognitive and affective development of students. Early childhood education is the child's access to first experiences in society, it is at this stage of life that he has the opportunity to build his hypotheses and learnings about the world; broaden your horizons and experience new experiences that will serve as a subsidy for your identity construction. In this sense, it was necessary to know a little more about the trajectory and the installation of Early Childhood Education in Brazil in order to arrive at the contemporary panorama. In this research methodology, qualitative and descriptive approaches were used, in order to reflect on the positive impacts of early childhood education on the educational lives of individuals. After collecting information, it was found that the recognition of the child as a social and historical subject makes Early Childhood Education an essential step for the legitimacy of citizenship and childhood.

Key words: Child Education, Cognitive Development, Learning.

\section{Introdução}

A Educação Infantil é o passo primordial na vida educacional da criança. É um mundo de descobertas e novas aprendizagens que potencializam as competências e

\footnotetext{
${ }^{1}$ Doutorando em Ciências da Educação pela Faculdade Interamericana de Ciências Sociais - FICS. Mestre em Ciências da Educação pela Faculdade Interamericana de Ciências Sociais - FICS. Especialista em arte Educação pelo Centro Universitário Leonardo Da Vinci. Especialista em Gestão Integrada: Administração, Supervisão e Inspeção pelo Instituto Superior de Educação Afonso Cláudio. Graduado em Pedagogia pela Faculdade de Tecnologia e Ciências - FTC. Docente do Ensino Fundamental pela Secretaria de Educação do Município de Camaçari. Email: guedes411@hotmail.com

${ }^{2}$ Mestre em Ciências da Educação pela Faculdade Interamericana de Ciências Sociais - FICS. Especialista em História da África pela UFRB.Especialista em Psicopedagogia pela FAC. Licenciada em Pedagogia pela UEFS. Docente da Rede Municipal de Educação de Santo Amaro-Ba. Email:. patinhaprof@gmail.com
} 
habilidades pueris indispensáveis no processo de construção do conhecimento. A proposta desta pesquisa é apresentar um estudo sobre a importância do Ensino Infantil para o desenvolvimento cognitivo e social dos educandos, sobretudo das escolas públicas brasileiras. Portanto, o mesmo traz um breve histórico sobre este segmento de ensino no país e suas modificações ao longo dos tempos.

Este trabalho se justifica pela necessidade e relevância de refletirmos sobre a Educação Infantil como elemento indispensável para a formação plena do indivíduo. Entender as etapas da infância e como as múltiplas inteligências podem ser estimuladas e mediadas de forma pontual e significativa nesta fase da vida é entender e valorizar a complexidade da formação do sujeito em suas diferentes trajetórias.

O objetivo geral desta pesquisa é descrever e analisar a importância da Educação Infantil para a socialização, formação e desenvolvimento dos educandos. E os objetivos específicos foram compreender as ações pedagógicas que estimulam a aprendizagem; refletir sobre as intervenções da educação infantil para formação integral dos educandos; e conhecer o percurso histórico da institucionalização da Educação Infantil no Brasil.

O reconhecimento da criança enquanto sujeito social e histórico faz da educação infantil um passo imprescindível para legitimidade da cidadania da infância, bem como da formação plena do indivíduo. Afinal, é nesta fase da vida que a criança adquire valores e aprendizagens que contribuirão para o seu crescimento individual. Vale salientar A LDB no seu art.29 assegura que:

\footnotetext{
A educação infantil é a primeira etapa da educação básica. Tem como finalidade o desenvolvimento integral da criança até 6 anos de idade, em seus aspectos físico, psicológico, intelectual e social, complementando a ação da família e da comunidade (BRASIL, 1996, [s/p]).
}

Nesta perspectiva, a Educação Infantil, sobretudo nas creches e escolas públicas, deve ser valorizada como mais um instrumento de formação intelectual, afetivo e social que em parceria com a família e os poderes públicos assegura que as crianças tenham a base escolar necessária para cursarem o Ensino Fundamental.

O problema norteador deste estudo parte do questionamento: Qual a importância da Educação Infantil para o desenvolvimento sócio-cognitivo da criança? A Educação Infantil é de grande relevância para o desenvolvimento escolar futuro da 
criança, uma vez que socializa, desenvolve habilidades, aperfeiçoa as capacidades motoras, afetivas, de relação interpessoal e inserção social.

Para responder a problemática a metodologia utilizada foi a exploratória qualitativa descritiva, as quais permitiram uma construção reflexiva e dialógica entre as discussões teóricas e as representações dos sujeitos que viabilizaram esta pesquisa.

Para apresentar um embasamento acerca do tema pesquisou-se 0 Referencial Curricular Nacional para a Educação Infantil; ideias e pressupostos teóricos de alguns autores sobre a temática estudada que serviram de referência para a realização da ação proposta.

\section{Constituição Histórica da Educação Infantil no Brasil}

A chegada da família real no ano de 1808 é marco decisivo nas mudanças que viriam ocorrer no Brasil no que diz respeito aos aspectos políticos, sociais, e educacionais do país. Foi neste momento que houve a quebra do ensino jesuítico colonial e começou a se pensar em outro modelo de educação que contemplasse prioritariamente a elite, e de forma menos privilegiada o povo, reforçando a desigualdade de tratamento que tem seus reflexos até os dias atuais (RIBEIRO, 2003).

Com a partida da família real para Portugal, o Brasil ficou nas mãos de D. Pedro como regente, no ano 1822 foi proclamada a República e novas mudanças ocorreram de modo que no ano de 1880 foi criada a primeira escola oficial do Rio de Janeiro, foi o ano também que a princesa Isabel assinou a Lei que acabava, pelo menos no papel, com a escravidão do Brasil. Então era preciso buscar novas formas de educação para o novo cenário social que se construía.

Diante de tantas mudanças ocorridas foi necessário pensar o que fazer com as crianças com menos de sete anos, já que a escola primária era destinada às crianças de sete a treze anos, e a escola secundária para as crianças a partir de treze. Até então a educação das crianças com idade inferior a sete anos ficava a encargo da mãe no âmbito caseiro e informal.

Os governadores brasileiros precisaram encontrar uma solução para acolher em instituições de ensino as crianças com menos de sete anos. O primeiro jardim de infância público brasileiro foi registrado no ano de 1896 na cidade de São Paulo e em 1899 foi fundado o Instituto de Proteção e Assistência à Infância do Rio de 
Janeiro $^{3}$ (IPAI-RJ) o qual futuramente se expandiria por todo território nacional. É neste mesmo ano que se inaugura no Rio de Janeiro uma creche que tinha vínculos com a Fábrica de Tecidos Corcovado e inicia a partir daí as creches vinculadas aos locais de trabalhos das mães operárias (RIBEIRO 2003).

Sob influência da Europa, onde ocorreu uma expansão de experiências pedagógicas inovadoras para a educação infantil, como o método criado por Maria Montessori, na Itália, e a de Ovide Declory, na Bélgica, aconteceu no Brasil uma revolução na educação, a partir daí começou-se o Movimento da Escola Nova, que levava em consideração o avanço da sociedade industrial e as ideias disseminadas na Europa. Os principais defensores deste movimento no Brasil foram Fernando Azevedo, Anísio Teixeira e Lourenço Filho.

Com as modificações sofridas no cenário socioeconômico, as mulheres sentiram a necessidade de trabalhar fora de casa, passando assim a ter que deixar seus filhos cada vez mais cedo nas creches e pré-escolas. Por isso, entende-se que:

\begin{abstract}
A urbanização, a crescente participação da mulher no mercado de trabalho extradomiciliar e as alterações na estrutura familiar são ainda hoje fatores determinantes da demanda social de creches e pré-escola. [...] Quando surge uma creche ou pré-escola, nova perspectiva abre-se para a mulher e para a criança, o melhor, para toda a família [...]. Mas a educação infantil não parou por ai. Várias ciências debruçaram-se sobre a criança, nos últimos cinquenta anos, entre elas a psicologia, a sociologia, a biologia e a psicanálise infantil (DIDONET, 1991, p.92).
\end{abstract}

O Estado se viu obrigado a criar políticas públicas que contemplassem a formação educacional do indivíduo em suas diferentes fases de crescimento. E só então no século $X X$, começa um maior investimento na educação no que tange à construção de escolas, de creches e de Universidades públicas, de forma que tentasse abranger o maior número de pessoas.

Apesar de previsto pela Constituição de 1988, como dever do Estado assegurar a Educação Infantil como parte do sistema de educação brasileira, só em 1996 a determinação ganha um estatuto formal mais detalhado com a criação da Lei de Diretrizes e Bases da Educação Nacional. Com isto a Educação Infantil começa a ser encarada com outros olhos que não a do assistencialismo, e inicia a nova fase de entender a infância pré-escolar como sendo um importante pilar para a formação educacional do indivíduo. É o que garante o artigo 29 da LDB, quando afirma que:

\footnotetext{
${ }^{3}$ Instituição filantrópica e grande obra de Moncorvo Filho. Vinte anos depois, 17 institutos similares estavam instalados em outros estados brasileiros.
} 
A educação infantil, primeira etapa da educação básica, tem com finalidade o desenvolvimento integral da criança até os seis anos de idade, em seus aspectos físico, psicológico, intelectual e social, complementando a ação da família e da comunidade (BRASIL, 1996, [s/p]).

Com isto, muda-se então a noção sobre infância, afinal a concepção da criança enquanto sujeito histórico e de direitos demorou muitos anos até ser entendida e aceita pela sociedade. Isso se deu porque a ideia de infância foi construída de forma gradual com o passar dos anos e das modificações políticas, pedagógicas e sociais sofridas por todas as gerações. Foi, portanto, necessário mudar a forma de olhar a criança, afinal:

Conceber a criança como ser social que ela é, significa: considerar que ela tem uma história, que pertence a uma classe social determinada, que estabelece relações definidas segundo seu contexto de origem, que apresenta uma linguagem decorrente dessas relações sociais e culturais estabelecidas, que ocupa um espaço que não é só geográfico, mas que também dá valor, ou seja, ela é valorizada de acordo com os padrões de seu contexto familiar e de acordo com sua própria inserção nesse contexto (KRAMER, 1986, p. 79).

A criança quando passa a ser vista como ser social começa a ocupar um novo lugar na sociedade. E neste novo espaço de representação é tida como um indivíduo que precisa ser entendido na sua totalidade e para isto é imprescindível que as relações interpessoais sejam incentivadas, mas acima de tudo que as peculiaridades da infância sejam respeitadas e valorizadas.

A constituição histórica da Educação Infantil no Brasil aconteceu à proporção que a própria infância foi reconhecida socialmente, sobretudo porque as relações sociais e políticas obrigaram o estado a rever o seu posicionamento sobre a educação das crianças brasileiras.

Diversas causas e concepções influenciaram o surgimento das instituições pré-escolares (creches, maternais, jardins de infância) no Brasil. Para melhor compreender essas motivações, é preciso lembrar que a princípio as creches e as pré-escolas tinham um caráter meramente assistencialista, com a única função de "guardar" as crianças até que suas mães chegassem do trabalho. Havia também as propostas pedagógicas de cunho religioso como forma de educação dentro destas instituições infantis.

Sabe-se que a história não se escreve através de fatos isolados e nem de forma linear, mas através de sucessão de acontecimentos, motivações e interesses que se completam e se entrelaçam formando a própria história. Sobre isso afirma-se que: 
A história das instituições pré-escolares não é uma sucessão de fatos que se somam, mas a interação de tempos, influências e temas, em que o período de elaboração da proposta educacional assistencialista se integra aos outros tempos da história dos homens (KUHLMANN, 1998, p. 77).

O formato de Educação Infantil que temos hoje é fruto de todas essas transformações, reformulações e estudos sobre a infância bem como a sua relevância para a construção identitária de cada indivíduo. Esse entrelaçar dos fatos compôs o conhecimento que temos hoje sobre o processo de aprendizagem da criança dentro das instituições de Educação Infantil.

Vale salientar que o formato e composição pedagógica da Educação Infantil foram se modificando com o passar dos anos. Na contemporaneidade, tem-se buscado cada vez mais o aperfeiçoamento do ensino desta modalidade respeitando o tempo de cada criança, bem como suas fases de desenvolvimento. Além disso, há uma preocupação com a formação docente para que atenda este público da maneira mais adequada e capacitada.

\title{
Desenvolvimento das Políticas Públicas Para Educação e Infância no Brasil
}

As mudanças de concepções a respeito da infância ao longo dos tempos motivaram a criação de diversas políticas públicas voltadas para o atendimento de crianças com até cinco anos de idade.

O mais importante de se analisar as políticas públicas para a infância no Brasil, é compreender a criação, execução e fiscalização de programas e projetos de vários ramos da sociedade com o intuito de buscar os melhores caminhos para garantir os direitos inerentes à pessoa, afinal:

\begin{abstract}
As políticas sociais se referem a ações que determinam o padrão de proteção social implementado pelo Estado, voltadas, em princípio, para a redistribuição dos benefícios sociais visando a diminuição das desigualdades estruturais produzidas pelo desenvolvimento socioeconômico. As políticas sociais têm suas raízes nos movimentos populares do século XIX, voltadas aos conflitos surgidos entre capital e trabalho, no desenvolvimento das primeiras revoluções industriais (HOFLING, 2001, p. 31).
\end{abstract}

$\mathrm{Na}$ década de 80 as reivindicações de direitos começaram a ficarem mais intensas. É neste período que é promulga a Constituição Federal de 1988, nela há a defesa dos direitos de todos os cidadãos brasileiros. A Constituição Federal de 1988 foi documento pioneiro na valorização e reconhecimento da infância, a partir dele derivaram outros que reforçaram a ideia de assistência educativa para este público (CESIARA, 2002). 
A Constituição Federal foi um avanço decisivo no que tange à educação como sendo um direito social de responsabilidade do Estado em parceria com a família. Observemos o que diz o artigo 205 desta Constituição:

A educação, direito de todos e dever do Estado e da família, será promovida e incentivada com a colaboração da sociedade, visando ao pleno desenvolvimento da pessoa, seu preparo para o exercício da cidadania e sua qualificação para o trabalho (BRASIL, 2010, [s/p]).

A dignidade da pessoa humana está contemplada nesta Constituição e consequentemente a promoção de igualdade entre os indivíduos está estritamente ligada ao direito de oportunidades gerados pela garantia de educação de qualidade para todos os cidadãos sem distinção de classe social.

Com o acesso à educação garantido por lei, foi imprescindível a criação de Estatutos e Leis específicas para fazer valer esses direitos garantidos a todos os cidadãos, sobretudo, para as crianças e os adolescentes. Nesta perspectiva, foi sancionada em 13 de julho de 1990 a Lei Federal 8.069, conhecida como Estatuto da Criança e do Adolescente 4 (ECA).

Neste novo paradigma, as crianças e os adolescentes passam a ser considerados como sujeitos de direitos com prioridades específicas já que possuem condições peculiares no contexto sociocultural. A ECA sinaliza a importância de políticas voltadas para garantia de direitos, pois:

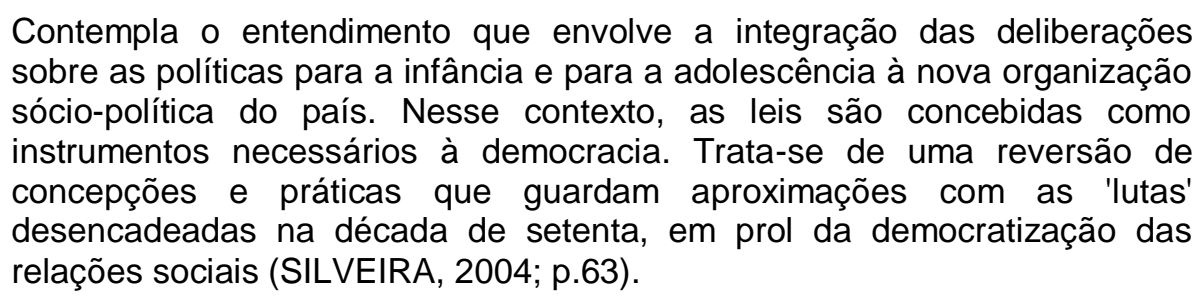

Com o advento da ECA houve uma crescente preocupação em garantir melhores condições de vida para esta parcela da sociedade que durante muito tempo não era reconhecida como merecedora de atenção e cuidados. Já em seu primeiro artigo o estatuto enfatiza a proteção integral da criança e do adolescente quando afirma que esta Lei dispõe sobre a proteção integral à criança e ao adolescente.

\footnotetext{
${ }^{4}$ Conjunto de normas do ordenamento jurídico brasileiro que tem como objetivo a proteção integral da criança e do adolescente, aplicando medidas e expedindo encaminhamentos para o juiz. É o marco legal e regulatório dos direitos humanos de crianças e adolescentes.
} 
$\mathrm{Na}$ esfera de ações significativas no âmbito da educação, a ECA introduziu o trabalho socioeducativo pautado na construção da cidadania e do respeito e não mais nas práticas assistencialistas defendidas outrora pelo Estado. Com este formato, foi imprescindível estabelecer linhas de ação da política de atendimento e programas sociais, serviços de prevenção, entidades de atendimento, medidas de proteção e organização pública voltada para as crianças e adolescentes.

A reinserção da família na construção dos valores e na formação identitária infanto-juvenil foi uma das prioridades defendidas pela ECA. Nesta perspectiva, a família exerce papel de grande relevância para garantia de direitos e acompanhamento da formação cidadã infanto-juvenil, sobretudo no que tange o processo de aprendizagem.

\title{
Educação Infantil: Desenvolvimento e Aprendizagem
}

A Educação Infantil é a primeira etapa da vida escolar da criança e por isso ocupa papel de destaque no que tange a sua formação educacional. Por ser a fase inicial da educação básica requer um cuidado específico tanto por parte das instituições e dos docentes quanto por parte da família.

Por entender a criança como um sujeito que necessita da interação com as pessoas e o ambiente para a aquisição de sua aprendizagem, é preciso garantir que as referências familiares, sociais e culturais façam parte de sua construção enquanto cidadão, afinal:

\begin{abstract}
A criança como todo ser humano, é um sujeito social e histórico e faz parte de uma organização familiar que está inserida em uma sociedade, com uma determinada cultura, em um determinado momento histórico. É profundamente marcada pelo meio social em que se desenvolve, mas também o marca. A criança tem na família, biológica ou não, um ponto de referência fundamental, apesar da multiplicidade de interações sociais que estabelece com outras instituições sociais (BRASIL, 1998, p. 21).
\end{abstract}

Como esclarece o Referencial Curricular Nacional para a Educação Infantil ${ }^{5}$ (RCNEI), a criança estabelece com os seus pares uma relação de extrema importância para a construção de sua subjetividade e interfere consideravelmente no ambiente que convive. Nesta perspectiva, a criança é um sujeito ativo no que diz respeito ao seu processo de desenvolvimento e aprendizagens.

\footnotetext{
${ }^{5}$ Integra a série de documentos dos Parâmetros Curriculares Nacionais elaborados pelo Ministério da Educação atendendo às determinações da Lei de Diretrizes e Bases da Educação Nacional (Lei 9.394/96)
} 
A construção de valores e o conhecimento que o indivíduo tem do mundo antecede o conhecimento formal aprendido nas escolas, por isso é imprescindível que as instituições escolares saibam valorizar e potencializar os diferentes saberes que a criança já traz consigo antes mesmo de frequentar a Educação Infantil. Desta forma, é importante ressaltar que:

A criança vai aprendendo a respeito do mundo em que está inserida, vai conhecendo seus valores, suas culturas. Esses valores sociais, entretanto, são frutos de experiências que a criança vai desenvolvendo junto com aprendizados e significados culturais que a rodeiam ao longo de sua vida. (MAIA, 2012, p. 33).

O processo de aprendizagem, neste sentido, está estritamente ligado ao ambiente em que cada criança está inserida e aos estímulos que este lugar pode transmitir-lhe, pois:

As mesmas condições ambientais - em crianças diferentes e em diferentes fases de desenvolvimento - podem exercer diferentes tipos de influências , assim como provocar diferentes atitudes, dependendo também do significado que cada criança atribui às situações vivenciadas e do nível de consciência que ela possui em relação aos acontecimentos. Enfim, cada criança interpreta, vivência e se relaciona com as situações cotidianas e do seu entorno sociocultural de forma particular (RAPOPORT et al, 2009, p. 38).

Cada criança tem seu jeito próprio de aprender, e suas peculiaridades devem ser respeitadas. As mesmas condições ambientais são interpretadas, sentidas e internalizadas de diferentes maneiras porque cada ser é único. Dessa forma, o processo de desenvolvimento e aprendizagem está vinculado às relações estabelecidas entre a criança e o contexto ambiental em que a mesma vive, uma vez que:

Cada função no desenvolvimento cultural de uma criança aparece duas vezes: primeiro no nível social e mais tarde, no nível individual, primeiro entre pessoas (interpsicológico) e depois dentro da criança (intrapsicológico). Isso se aplica igualmente a toda atenção voluntária, à memória, à formação de conceitos. Todas as ações mentais superiores se originam como relações reais entre pessoas (VYGOTSKY, 1978, p.57).

Percebe-se com esta citação, a importância que o teórico atribui às relações interpessoais como pressupostos para a construção identitária e de saberes. Afinal, enquanto seres sociais o indivíduo depende do outro para (re) significar a sua própria autonomia.

$\mathrm{Na}$ Educação Infantil o processo de aquisição do conhecimento se dá de forma lúdica e dinâmica porque é através das representações simbólicas que as crianças desenvolvem suas ideias, criam suas hipóteses, formulam conceitos e 
estabelecem relações lógicas. Nesta perspectiva, a utilização de atividades lúdicas e de material concreto está estritamente relacionada ao processo de construção do conhecimento, por isso é essencial que o ambiente da Educação Infantil estimule e desafie a criança a buscar novas estratégias para o desenvolvimento cognitivo, afinal:

O brincar é uma atividade humana criadora, na qual imaginação, fantasia e realidade interagem na produção de novas possibilidades de interpretação, de expressão e de ação pelas crianças, assim como de novas formas de construir relações sociais com outros sujeitos, crianças e adultos (VYGOTSKY, 2007, p. 35).

A aprendizagem é um processo gradativo que é fortalecido durante a Educação Infantil, é neste período de interação da criança com outras crianças, com o docente e com o meio ambiente que há o favorecimento da construção desta aprendizagem, isto por que:

\begin{abstract}
Aprendizagem é o processo pelo qual o indivíduo adquire informações, habilidades, atitudes, valores, etc. a partir de seu contato com a realidade, 0 meio ambiente, as outras pessoas. É um processo que se diferencia dos fatores inatos (a capacidade de digestão, por exemplo, que já nasce com o indivíduo) e dos processos de maturação do organismo, independentes da informação do ambiente (a maturação sexual, por exemplo). Em Vygotsky, justamente por sua ênfase nos processos sócio-históricos, a idéia de aprendizado inclui a interdependência dos indivíduos envolvidos no processo. (...) o conceito em Vygotsky tem um significado mais abrangente, sempre envolvendo interação social (OLIVEIRA, 1997, p. 57)
\end{abstract}

\title{
De acordo com o Referencial Curricular Nacional da Educação Infantil
}

Educar significa, portanto, propiciar situações de cuidado, brincadeiras e aprendizagem orientadas de forma integrada e que possam contribuir para o desenvolvimento das capacidades infantis de relação interpessoal de ser e estar com os outros em uma atitude básica de aceitação, respeito e confiança, e o acesso, pelas crianças aos conhecimentos mais amplos da realidade social e cultural (BRASIL, 1998, v.01 p. 23).

Fica evidente, portanto que o processo de ensino-aprendizagem da Educação Infantil ocorre de forma diferenciada dos outros segmentos de ensino porque exige do docente e das instituições escolares um olhar mais cuidadoso, dinâmico e lúdico em relação à construção do conhecimento.

\section{Considerações}

O estudo aqui apresentado buscou refletir sobre a importância da Educação Infantil para construção social, cidadã e cognitiva dos indivíduos que iniciam sua vida escolar. Através desta pesquisa foi possível ratificar a concepção de que a Educação Infantil é um segmento de ensino indispensável no processo de 
construção do conhecimento, pois é a partir dela que a criança é estimulada a desenvolver diferentes competências e habilidades através da troca de saberes entre seus pares.

A Educação Infantil é a etapa primordial na vida escolar de todo indivíduo e por isso necessita de uma atenção especial no que tange os cuidados e ensino dispensados aos pequenos. A sala de aula é um espaço importante para a socialização da criança com outras pessoas. Neste ambiente de descobertas e aprendizagens é que o aluno desperta o senso de responsabilidade, curiosidade e afeição.

A criança deve ser vista e valorizada como um ser dotado potencialidades que precisam ser estimuladas, sempre respeitando o outro, aprendendo a conviver com as diferenças, tendo empatia por seus pares.

Após esta pesquisa constata-se que os princípios morais devem ser trabalhados na Educação Infantil de modo que defenda em suas ações pedagógicas a importância de estabelecer laços e de construir uma relação mútua pautada no respeito à diversidade.

A tomada de consciência desses novos tempos que vivencia-se com os avanços e mudanças no cenário sociocultural, configura uma exigência da Educação Infantil pautada no compromisso, integração e participação de todos os envolvidos no processo de ensino-aprendizagem.

Levando em consideração estes novos tempos é que salienta que o saber estimulado na Educação Infantil deve ser capaz de fomentar a criticidade e a reflexão através de atividades lúdicas e significativas que promovam a interação, participação.

As escolas de Educação Infantil devem, portanto, propor um educar que priorize o desenvolvimento íntegro e integral de seus educandos, para que os mesmos possam ser capazes de interagir e participar ativamente da sua construção pessoal e identitária ampliando questões que possam favorecer a sua cidadania.

Educar é possibilitar diálogos que viabilizam maior socialização e reflexão sobre o contexto a qual estamos inseridos. A ação de educar inexiste quando nos prendemos ao ensino técnico transmissivo sem construção conjunta e gradativa. Educar transcende o modo conteudista e desprovido de significado, para, além disso, o ofício de educar deve entrelaçar saberes, habilidades e competências no intuito de oferecer à criança uma condição ética de estar no mundo e fazer parte dele. 
O estudo em questão permitiu observar e refletir sobre a importância das relações estabelecidas no processo educativo da Educação Infantil. Ficou evidente durante as observações que é na coletividade que o indivíduo se concerne como pessoa e como cidadã. Entender os processos de aprendizagem da criança é compreender a sua subjetividade e peculiaridade que Ihes torna única, neste sentido o ensino da Educação Infantil deve promover e despertar o interesse da criança em aprender com o outro de forma dialógica e lúdica.

\section{Referências:}

BRASIL, Lei de Diretrizes e Bases. Lei no 9.394/96 Brasília: MEC/SEF, 1996.

BRASIL, Ministério da Educação e do Desporto, Secretaria de Educação Fundamental. Parâmetros curriculares nacionais. Brasília: MEC/SEF, 1998.

BRASIL. Ministério da Educação e do Desporto. Secretaria de Educação Fundamental. Referencial Curricular Nacional para a Educação Infantil. Brasília: MEC/SEF, 1998.

BRASIL Ministério da Educação. Secretaria de Educação Básica. Programa Nacional de Fortalecimento dos Conselhos Escolares. Brasília, 2004.

BRASIL. Constituição de 1988. Constituição da República Federativa do Brasil. Brasília, DF, Senado, 2010.

CERISARA, A. B. O Referencial Curricular Nacional para a Educação Infantil no Contexto das Reformas. Educação \& Sociedade. Revista de Ciência da Educação. Campinas - Vol. 23, n. 80, set., 2002.

FREIRE, P. Pedagogia da autonomia: saberes necessários à prática educativa. São Paulo: Paz e terra, 1996.

HÖFLING, E. de M. Estado e Políticas (Públicas) Sociais. Cadernos CEDES, Campinas, ano XXI, n. 55, p. 30-41, nov. 2001.

KUHLMANN, M. Jr. Infância e Educação Infantil uma abordagem histórica. Porto Alegre: Editora Mediação, 1998.

RAPOPORT, A.; SARMENTO, D. F.; NÖRNBERG, M. P. A criança de 6 anos no ensino fundamental. Porto Alegre: Mediação, 2009. 